\title{
Distribution and status of Coffee Berry Disease (CBD) in Arsi, Southeastern Ethiopia
}

\author{
Hika Bersisa $^{1}$, Mashilla Dejene ${ }^{2}$ and Eshetu Derso ${ }^{2}$ \\ ${ }^{1}$ Mechara Agricultural Research Center, Mechara, Ethiopia \\ ${ }^{2}$ School of Plant Sciences, Haramaya University, Ethiopia, \\ ${ }^{3}$ Ethiopian Agricultural Research Institute, Addis Abeba, Ethiopia
}

How to cite this paper: Bersisa, $\mathrm{H}$., Dejene, M., Derso, E. (2018) Distribution and status of Coffee Berry Disease (CBD) in Arsi, Southeastern Ethiopia. International journal of food science and agriculture, 2(6), 108-117. DOI: $10.26855 /$ ijfsa.2018.11.001

Corresponding author: Hika Bersisa, Mechara Agricultural Research Center, Mechara, Ethiopia E-mail: hikbersisa@gmail.com

\begin{abstract}
Coffee is a non-alcoholic and stimulant beverage crop and belongs to the family Rubiaceae and genus Coffea. Arabica coffee (Coffea arabica L.) has been threatened by various coffee fungal diseases. Among these coffee berry disease (CBD) is the most economically important one in East African countries including Ethiopia. Coffee berry disease (CBD) caused by Colletotrichum kahawae was intensively assessed and examined in 90 sample coffee farms from 3 coffee growing districts (Chole, Gololcha and Shanan Kolu) of Arsi, Southeastern Ethiopia. Assessment was done to examine prevalence, incidence and severity of CBD in selected districts. Assessment was done visually, random sampling techniques and interviewing growers for important points related to CBD. Coffee berry disease was prevalent in most surveyed coffee growing areas of Arsi. The overall mean prevalence, incidence and severity of CBD were 85.52, 49.78 and $19.25 \%$, respectively. The highest incidence (100\%) and severity $(55.14 \%)$ of CBD were observed in Shanan Kolu, followed by Gololcha, 80 and 54.18\% and Chole, 80 and $42.73 \%$. High CBD se verity and incidence were recorded at the high land of selected districts. In order to reduce CBD intensity in the respective areas, research should be able to develop CBD resistant coffee varieties through screening landraces using virulent pathogens. Similarly, proper cultural practices, such as coffee pruning, shade tree regulation, application of organic fertilizers and wider spacing should be utilized by coffee growers to reduce CBD intensity throughout their coffee ecosystem.
\end{abstract}

Keywords

Arabica coffee, Coffee berry disease, incidence, prevalence, severity.

\section{Introduction}

Arabica coffee (Coffea arabica L.) is a non-alcoholic and stimulant beverage crop that belongs to the family Rubiaceae and genus Coffea. Among the hundred species of Coffea genus, only Arabica coffee (Coffea arabica L.) and Robusta coffee (Coffea canephora L.) species have been commercially cultivated worldwide (Kimani et al., 2002; Waller et al., 2007). Arabica coffee is indigenous to Ethiopia. Forests in Southwestern Ethiopia are the primary center of origin and genetic diversity of Arabica coffee (Melaku, 1984).Currently it has been produced in more than 80 countries of the world highlands, while Robusta coffee is more cultivated in the lowlands than in the highlands of the tropical and subtropical coffee-producing countries in the world. Arabica coffee is more popular worldwide due its bean quality. As a result, Arabica coffee accounts for about $70 \%$ of the world coffee trade, while Robusta coffee contributes to about 30\% (ICO, 2016). 
Coffee crop is the most important agricultural commodity, worth an estimated retail value of USD 70 billion, crucial for the economy of more than 70 countries and the main income resource for hundreds of millions people worldwide (ICO, 2016). Coffee has been Ethiopia's largest export crop commodity and earning foreign currency.

However, Coffea Arabica, is nowadays more threatened by various constraints in all coffee-producing countries of the world. Among these, fungal coffee diseases are most economically important in reducing coffee production. Coffee berry disease (CBD) is an anthracnose of green coffee berries caused by the fungus Colletotrichum kahawae Waller and Bridge and has been a serious disease to Arabica coffee and poses considerable losses on crop in East Africa, including Ethiopia (Vander graf, 1981, Eshetu, 1997).

According to Jima et al. (2016) 80\% of farmers' livelihood has been dependent on Arabica coffee production in coffee growing areas of Arsi. However, study related to coffee berry disease was limited in Arsi coffee growing areas namely Chole, Gololcha and Shanan Kolu. Thus, the present study was conducted to assess coffee berry disease prevalence, incidence and severity at the above mentioned locations in Arsi.

\section{Materials and methods}

\subsection{Description of the study area}

The study was conducted in the three districts of Arsi Zone namely Chole, Gololcha, and Shanan Kolu, Southeastern Ethiopia in 2017. Arsi coffee growing belts occurred in southeastern part of Ethiopia and were located between the range of $08^{\circ} 04^{\prime}$ to $08^{\circ} 33^{\prime} \mathrm{N}$ latitude and $039^{\circ} 59^{\prime}$ to $040^{\circ} 15^{\prime} \mathrm{E}$ longitude from the equator. The minimum and maximum altitude of the surveyed areas were 1537 and $2075 \mathrm{~m}$. a. s.l. respectively. While the annual temperature and rain fall of Chole, Gololcha and Shanan Kolu is 25 and 1000, 27 and 900, and $23^{\circ} \mathrm{C}$ and $1100 \mathrm{~mm}$ respectively.

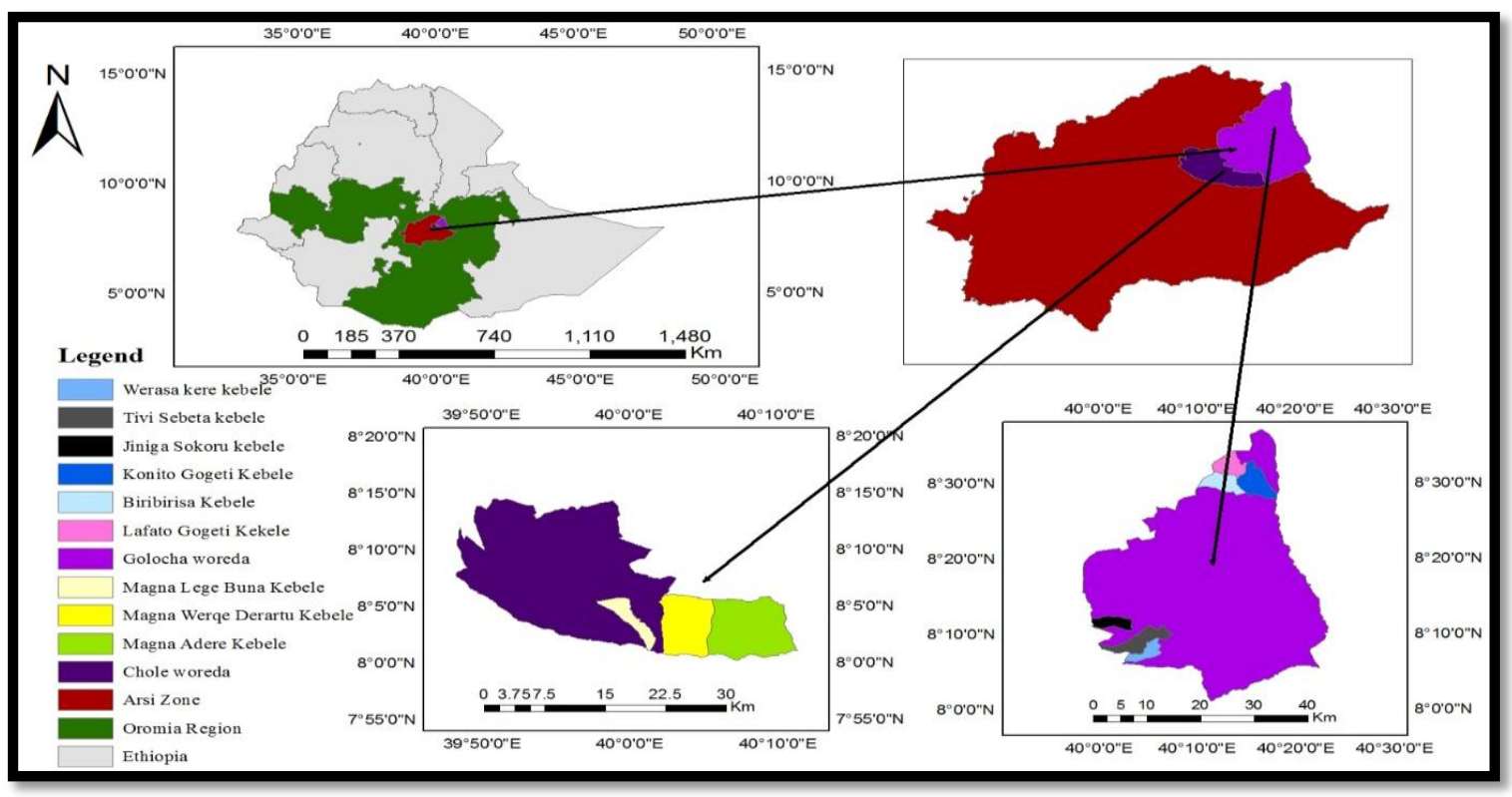

Figure 1. Location map of surveyed areas of Arsi Zone.

\subsection{Assessment of coffee berry disease (CBD)}

Incidence assessment: thirty trees per farm were randomly taken and diagnosed visually for presence and absence of CBD on each tree. Then after, disease incidence was calculated as (Number of diseased trees/total observed trees) x 100.

Severity assessment: ten trees per farm were randomly taken and each tree was divided into three strata of branches (top, middle and bottom). From each stratum, one pair of branches were selected to compute disease severity. CBD damaged and healthy berries were counted and then percentage of diseased berries over total counted berries was calculated.

Prevalence: the selected farms were visually assessed for presence and absence of CBD. Finally disease distribution was calculated as number of infected farm from the total assessed farms) x 100.

\subsection{Sampling techniques}


Farm samples were taken at an interval of $5 \mathrm{~km}$ along the main and accessible rural roads from August to September 2017 cropping season. Three Farmers' Associations (FAs) were selected per district, while 10 farms were selected per FA. On the other hand, 9 and 90 representative FAs and coffee farms were assessed, respectively, across districts. Accordingly, 30 and 10 representative coffee trees per farm were taken randomly for incidence and severity, respectively. Totally, 900 and 300 coffee trees per district and 2700 and 900 coffee mother trees from overall selected districts were assessed visually for incidence and severity.

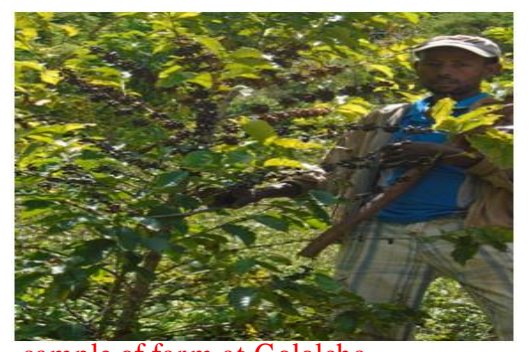

sample of farm at Gololcha

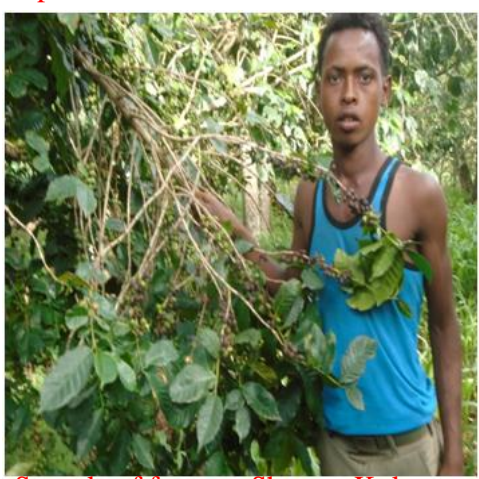

Sample of farm at Shanan Kolu

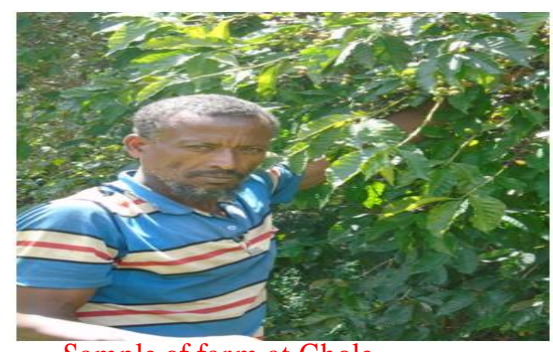

Sample of farm at Chole

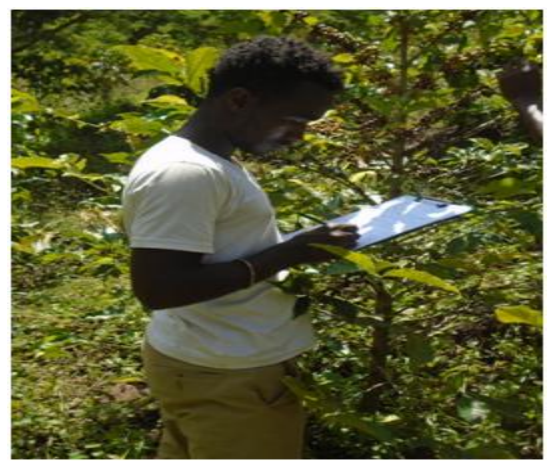

Sample of taking data

Figure 2. Samples of farms infected with CBD across to assessed districts and data taking sample.

\subsection{Data management and analysis}

All data collected from field was fed into computer and managed by using Excel Spread Data Sheet. Then finally the managed data was analyzed using IBM SPSS Statistics 20.

\section{Results and Discussion}

\subsection{Coffee berry disease occurrence and intensity}

Coffee berry disease (C. kahawae) was observed in all selected coffee growing areas of Arsi. It was recorded with different intensity among and within assessed districts. On the other hand, it means that frequency and intensity of CBD varied significantly $(\mathrm{p}<0.05)$ among and within districts. Other, coffee diseases like coffee wilt disease, coffee leaf rust, brown leaf spot and bacterial blight of coffee were also observed in the districts. According to Berhanu (2014) incidence and severity of coffee berry disease varied among and within Hararghe coffee growing districts. Similarly, Abdi and Abu (2015) observed different CBD intensity in districts of Borena and Guji zones. According to Kumlachew et al. (2016) there were variation in CBD intensity among and within Jimma, Ilubabor, Kombolcha, and Gedeo.

The survey result indicated that there was variation in CBD distribution and status among and within districts. The overall CBD mean and standard deviation of prevalence, incidence and severity across the surveyed areas with values of 85.52, 49.78, 19.25\% and 14.05, 21.82, 15.47\% (Table 1), respectively. On the hand, there were variations among FAs and also coffee farms. Such variations might have occurred due to the presence of diverse environmental conditions, including temperature, rainfall distribution, relative humidity, management and cultural practices undertaken by coffee growers and genetic diversity of Arabica coffee grown in the survey areas of Arsi Zone. 
Table 1. Overall minimum, maximum, mean and standard deviation of incidence, severity and prevalence of CBD

\begin{tabular}{llllll}
\hline Variables & Min & Max & Mean & $\begin{array}{l}\text { Standard Devia- } \\
\text { tion }\end{array}$ \\
\hline Incidence & 0 & 100 & 49.78 & 21.82 \\
Severity & 0 & 55.14 & 19.25 & 15.47 \\
Prevalence & 0 & 98 & 85.52 & 14.05 & \\
\hline
\end{tabular}

\subsubsection{Coffee berry disease prevalence}

Coffee berry disease (C. kahawae), was observed in most surveyed areas. The maximum (98\%) CBD prevalence was recorded in Gololcha, followed by Shanan Kolu (96\%) and Chole (95\%). The mean prevalence of CBD was 79.87, 89.57 and $87.13 \%$ at Chole, Gololcha and Shanan Kolu, respectively (Figure 2), while the overall average CBD prevalence was $85.52 \%$. The disease prevalence varied from district to district, even from kebele to kebele. It indicates that more CBD infected coffee farms were observed at Gololcha than in the two remaining districts, followed by Shanan Kolu and Chole.

CBD prevalence was 38.8 and $17.2 \%$ in Oromia and Southern Nations, Nationalities and Peoples' Region (SNNPR), respectively (IAR, 1997). In previous report of Berhanu (2014) CBD was prevalent in West and East Hararghe Zones. While a recent study conducted in Borena and Guji Zones revealed that CBD prevalence was 100\% in each of the surveyed district with an overall mean of $100 \%$ (Abdi and Abu, 2015). All in all CBD was prevalent with different levels of infection (values) in the entire coffee growing regions of the country. In the Ethiopian context, the high CBD occurrence might be associated with high humidity with corresponding high altitude around Gera. In various earlier and recent studies, CBD was prevalent at higher elevations, which is naturally characterized by optimum relative humidity favoring the pathogen (Bayetta, 2001; Fekadu, 2013; Birhanu, 2014; Abdi and Abu, 2015; Kumlachew et al., 2016). Accordingly, in the present study CBD was prevalent more on coffee farms relatively at high altitudes of Shanan Kolu and to some extent at Gololcha district.

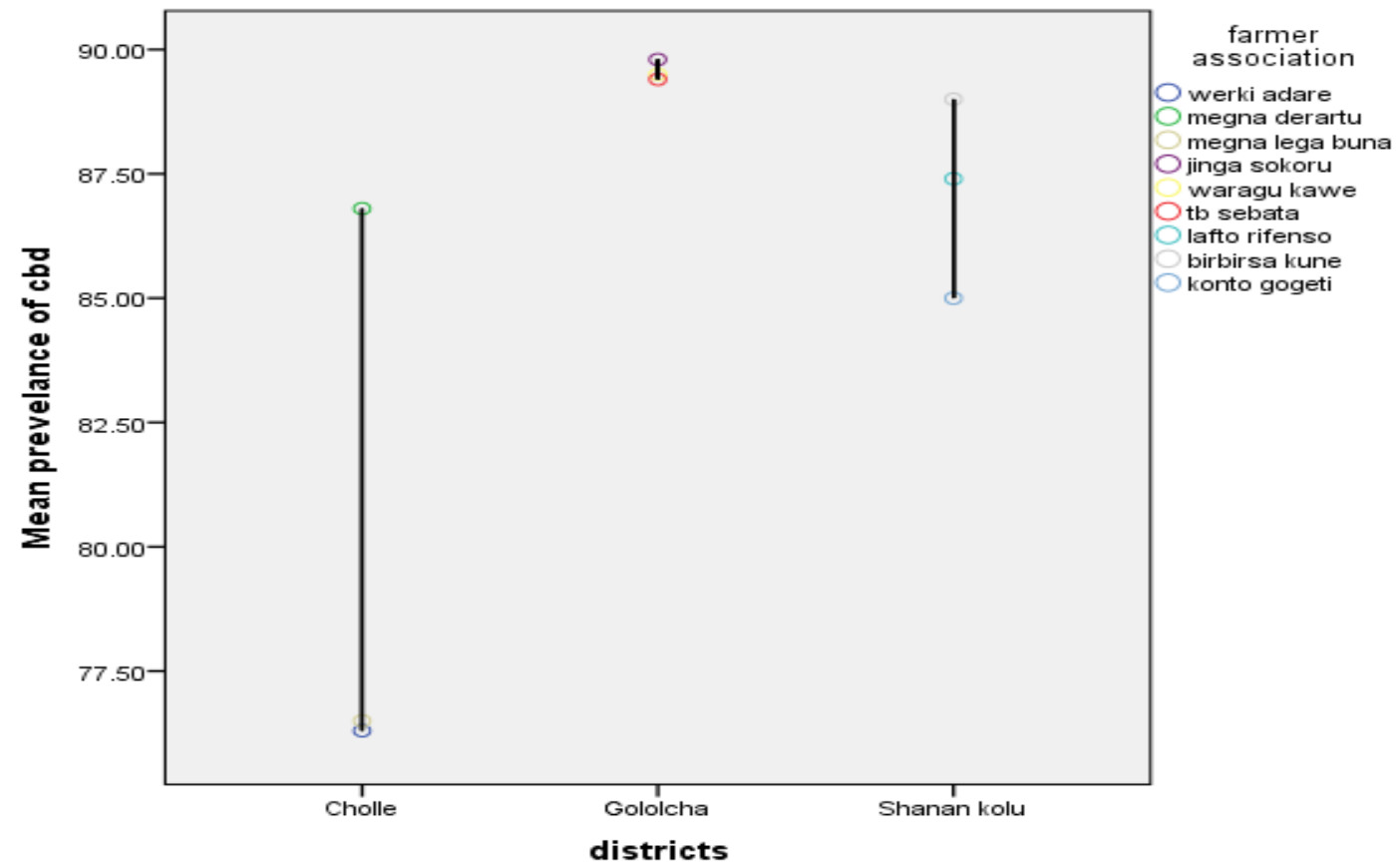

Figure 3. Mean prevalence of CBD per coffee-growing district of Arsi

\subsubsection{Coffee berry disease incidence}


The overall mean incidence of CBD recorded across the assessed districts was $49.78 \%$. However, at district level CBD incidence scored up to $100 \%$ at Shanan Kolu, followed by both Gololcha and Chole (80\%). Accordingly, the CBD mean incidence ranged between 6.67 - 60, 23.33 - 65, and 20 - 80\% in Chole, Gololcha and Shanan Kolu, respectively. But, the overall mean incidence per district was 41.89, 54.22 and 56\% at Chole, Gololcha and Shanan Kolu, respectively(Figure 3). The findings indicated that CBD incidence varied significantly from district to district, even from kebele to kebele. This variation might be due to host genetic diversity, environmental conditions, cultural practices undertaken by growers at different places and pathogen virulence.

Similar results were reported on CBD incidence at Gedeo, Jimma, Kombolcha and Sidama (Kumlachew et al.,2016). Abdi and Abu (2015) reported 49.3 and 14.8\% CBD overall mean incidence and severity in Borena and Guji respectively. According to Kumlachew et al. (2016) sixty percent of the surveyed coffee-producing districts had significantly higher levels of CBD incidence that ranged from 50 to 80\%. It indicates increased proportions of CBD infected coffee trees in Bedeno, Kombolcha and Gomma districts with respective incidences of 80, 75.6 and 70.0\% (Kumlachew et al., 2016).Berhanu (2014) recorded the highest (75\%) and lowest (51\%) CBD incidence from Bedeno and Daro Labu, respectively. Similarly, the highest (100\%) and lowest (80\%) CBD incidence was recorded from Shanan Kolu and Chole, respectively.

In context of surveyed areas, the assessment result indicates that the highest infection by CBD occurred at high elevation (>1750m.a.s.l.) as well as medium to low infection at medium to lower elevations $(1750-1500 \mathrm{~m}$. a.s.l.). This finding made it clear that pyramidal disease relationship occurred among CBD, elevation, moisture and temperature. On the other hand, from the equator to polar, the elevation increases, while temperature decreases with optimum relative humidity, which favors CBD development. Wayesa et al. (2017) explained that high rainfall, high humidity or wetness and relatively low temperature that persists for long periods favor CBD development and the disease is invariably severe at higher altitudes where these conditions generally exist. Therefore, geographically distribution of CBD varied from place to place.

\subsubsection{Coffee berry disease severity}

Among the overall assessed coffee farms, Shanan Kolu exhibited more CBD severity than farms surveyed in the remaining coffee-growing districts. The highest (55.14\%) CBD severity was recorded in Shanan Kolu, followed by Gololcha (54.18\%) and Chole (42.73\%). The overall mean severity per district was 12.67, 19.56 and 25.52 in Chole, Gololcha and Shanan Kolu, respectively (Figure 4). It means that CBD severity was different from district to district, even from kebele to kebele. It was also recorded with different severity levels that again varied from farm to farm and from coffee tree to coffee tree. This dissimilarity might indicate coffee genetic diversity, diverse environmental conditions, diverse agronomic practices, pathogen virulence and CBD management measures undertaken by growers from place to place. The present study confirms the previous works conducted under different agro-ecologies. For instance Arega (2006) reported varied CBD severity from various coffee forest areas. In the same study severity recorded from Bonga, Yayu,

Harena and Sheko with 17.9, 4.0, 5.4 and 2\%, respectively. Berhanu (2014) recorded CBD severity with $26 \%$ at Boke and 50\% at Bedeno. Similar results were reported by Abdi and Abu (2015) from Borena and Guji Zones that was 14.8\% CBD mean severity.

During the field survey, data were collected from both well-developed CBD symptom active lesions (black sunken lesion) and scab lesions. On the other hand, the occurrence of these two symptoms indicated the presence of coffee genetic diversity, diverse environmental conditions relative to coffee shade and management variation within and among coffee farms as well as within and among districts. Scab lesion appeared due to presence of unfavorable environmental conditions among and within farm as well as coffee trees, which may be dynamic related to different status of coffee shade trees that change micro climate of disease development component like relative humidity. Two types of active lesions with coffee berries were also observed at survey time. The former was active lesion with the enlarged size as well as more than three black colored dots were seen. Whereas, the latter was a dot or with one black dot alone. Concerning host pathogen interaction (genetics of pathogen and host), the second type of active lesion confirms incompatibility of host pathogen interaction, i.e. it indicated expression of hypersensitive reaction, which appeared as conferred by resistant genes. 


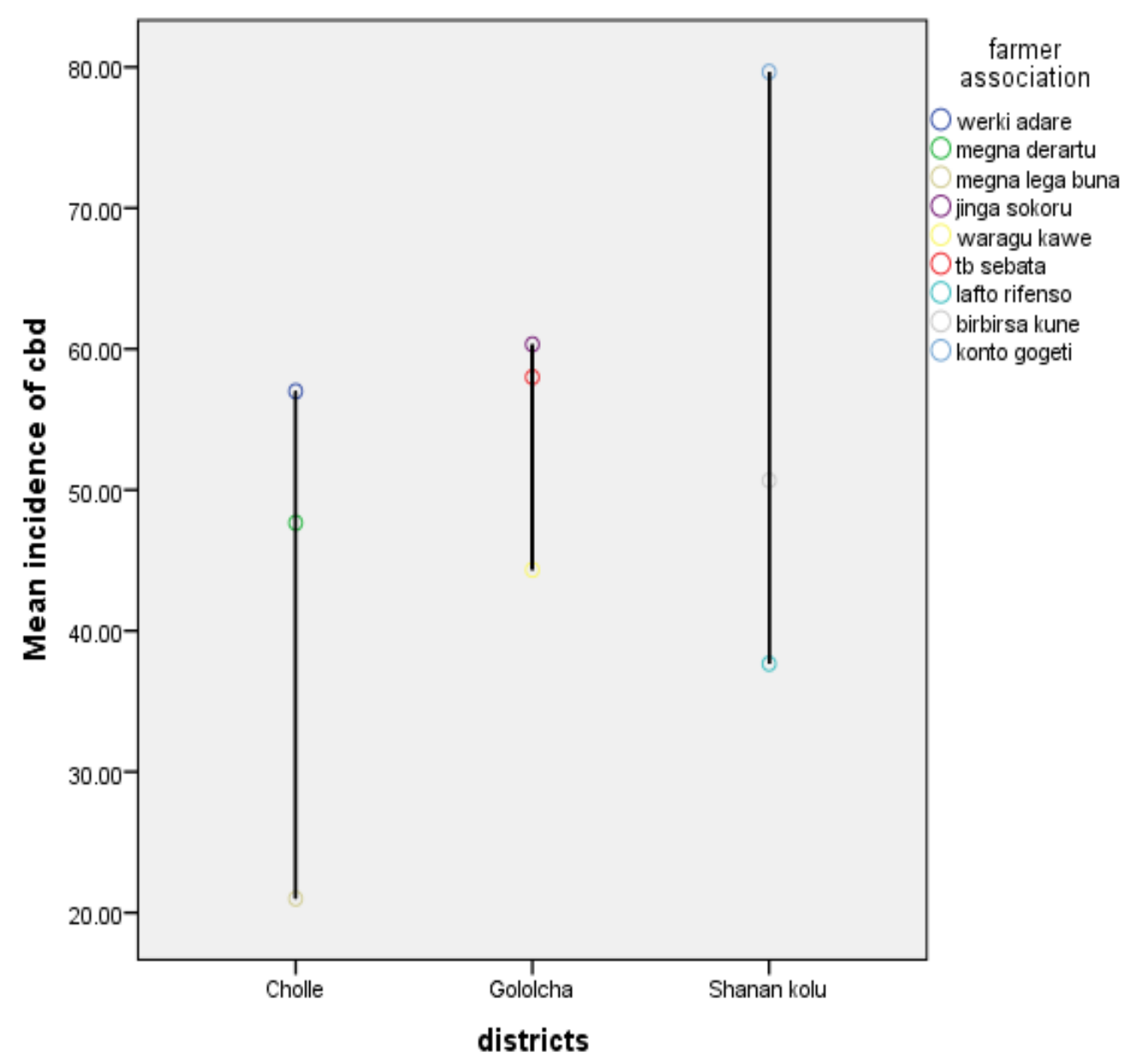

Figure 4. Mean incidence of CBD in coffee-growing districts of Arsi Zone.

According to Abdi and Abu (2015) this spread and scale of epidemics could be due to the use of a limited number of varieties and uniform cultural practices in the entire study areas. The same trend was practiced by Arsi coffee growers. Hundred percent of coffee cultivated in Chole, Gololcha and Shanan Kolu were local cultivars only. The recent CBD assessment report showed different severity at different coffee-growing areas (Kumlachew et al., 2016). The highest $(46.7 \%)$ disease severity was recorded in Gedeo, followed by Hararghe (42.7\%) and Jimma (32.0\%) (Kumlachew et al., 2016). 


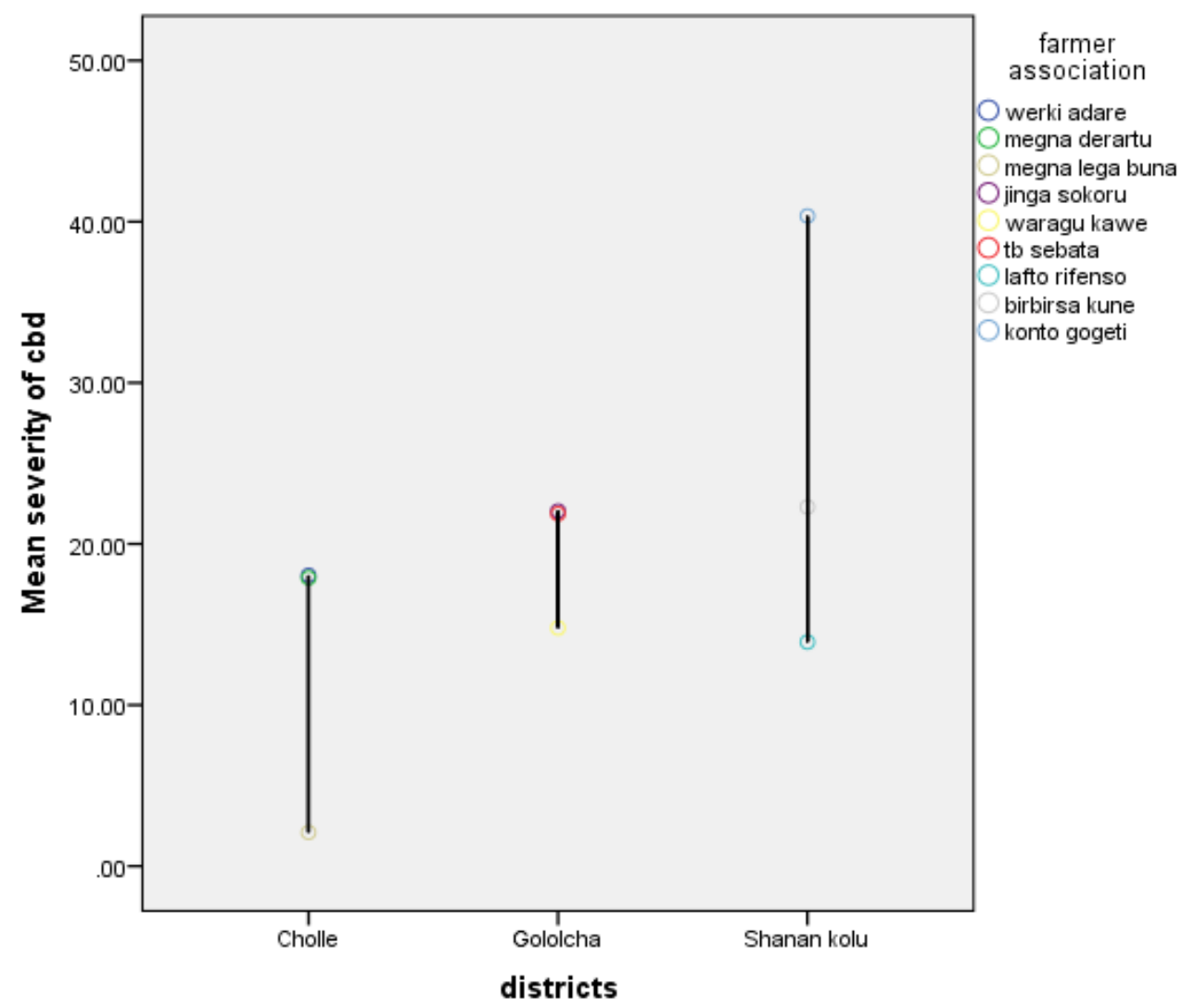

Figure 5. CBD mean severity in coffee-growing districts of Arsi Zone.

\subsection{Correlation of coffee berry disease occurrence and promoting factors}

\subsubsection{Correlation between altitude and coffee berry disease}

There was a positive correlation and significant $(\mathrm{p}<0.05)$ between CBD incidence and altitude $(\mathrm{r}=0.013)$, severity $(\mathrm{r}=$ $0.012)$ and prevalence $(r=0.015)$ of $\mathrm{CBD}$, indicating strong relationship between disease intensity and altitude (Table 2$)$. CBD incidence and severity has increased with altitude. However, one should bear in mind that the most determining factors are weather variables viz., temperature, humidity and moisture. All coffee-growing districts assessed for CBD distribution lied in mid to higher altitude (> 1537m.a.s.l.). Highest $(100 \%)$ and lowest $(80 \%)$ CBD incidence was recorded from higher altitudes $(>1750 \mathrm{~m}$.a.s.l.) of Shanan Kolu and mid to lowest altitude $(\geq 1500 \mathrm{~m}$.a.s.l.) of Chole, respectively. This indicates formation of conducive environment for epidemiological progression of the pathogen (C. kahawae) at these areas.

Berhanu (2014) reported low (51\%) and high (75\%) CBD incidence from lower altitude of Daro Labu and higher altitude of Bedeno, respectively, while lower (26\%) and higher (50\%) CBD severity was recorded from lower altitude of Boke and higher altitude of Bedeno, respectively. Abdi and Abu (2015) also demonstrated similar results in Borena and Guji coffee-growing Zones. Kumlachew et al. (2016) reported high CBD intensity (that ranged from 35.9 to 51.3\%) in the higher altitude of Bedeno, Kombolcha, Wonago, Yirgacheffee, Wonsho, Gimbi, Gomma and Gera. whereas lower disease intensity $(<22 \%)$ was exhibited at lower altitude of Abaya, Chora and Yayu, which are found at $<1500 \mathrm{~m}$.a.s.l. Similar trends were reported by Zeru et al. (2009) at lower elevation of Harena forest, Bale.

However, high CBD intensity does not always appear with increase in altitude unless there is optimum relative humidity and temperature. For the occurrence of a disease, there must be three major elements, namely susceptible host, conducive environment and virulent pathogen strain. Therefore, altitude and disease occurrence may not always go parallel to each other unless the required temperature and moisture exist.

\subsubsection{Correlation of husbandry management practices and coffee berry disease}


The correlation between cultural practices and the level of CBD infection was highly significant $(\mathrm{p}<0.05)$ and correlated negatively, incidence $(r=-0.234)$, severity $(r=-0.200)$ and prevalence $(r=-0.111)$ (Table 2). Major coffee farms $(74.4 \%)$ were managed by using cultural practices to reduce CBD incidence, while the remaining (25.6\%) farms remained under poor management and suffered to CBD. Those CBD management practices are; removal of unhealthy coffee trees from their farm, planting tolerant local cultivars, pruning of shade trees and clearing mummified berry leftover on coffee mother tree. The highest disease incidence was recorded from farms poorly managed, while moderate to least CBD incidence was demonstrated with moderately managed coffee farms.

These cultural practices helped to decline disease incidence by reducing the potential sources of primary inoculum (Bedimo et al., 2007; Kumlachew et al., 2016Cultural practices made by growers reduce the influences of the important disease element. Particularly pruning and shade regulation could reduce moisture content with coffee canopy via increasing ventilation, which eventually result in reduction of CBD incidence among and within coffee farms.

\subsubsection{Correlation of shade tree and coffee berry disease}

There was a negative correlation between shade tree and incidence $(r=-0.003)$, severity $(r=-0.091)$ and prevalence $(r=$ -0.206) of CBD (Table 2). The survey result indicated that low CBD intensity was exhibited with fully shaded coffee farms, while moderate and high disease intensity was recorded from semi-shaded and open sun coffee farms, respectively. Most (63.3\%) of coffee farms assessed for CBD distribution were fully covered with different recommended leguminous tree species, while the remaining coffee farms were covered with semi-shaded (30\%) and open sun (6.7\%).

Bedimo et al. (2008) recorded high and low CBD incidence from open sun and shaded farms, respectively. The infection rate for coffee trees under artificial shade estimated at $30 \%$ of diseased berries, while for the coffee trees without shade was 50\% (Bedimo et al., 2008). Accordingly, shade can also be used as a barrier and limit the splash dispersal of the pathogen. The disease severity is higher on coffee trees exposed to sunlight than on those located under the shade (Mouen et al., 2008). Kebati et al. (2016) reported that CBD infection was higher (57.40\%) in non-shaded than shaded coffee trees $(45.08 \%)$ in Kenya. They also demonstrated that the total berry loss was higher $(75.73 \%)$ in none shaded than shaded coffee $(63.65 \%)$. In fact, shade limit the rain intensity and consequently the splash dispersal of C. kahawae as has been already mentioned in other studies for several pathogens, particularly with Colletotrichum spp. (Ntahimpera et al., 1998; Ntahimpera et al., 1999). Artificial shading was found to reduce the CBD incidence on coffee trees when compared to non-shaded coffee (Kebati et al., 2016). Similar reports revealed that shading modifies the micro-climate of disease development (Bedimo et al., 2008).

\subsubsection{Correlation of coffee land-race and coffee berry disease}

There was a positive correlation between coffee landrace grown and CBD incidence $(r=0.012)$ and prevalence $(r=$ $0.175)$, while these landrace and CBD severity $(r=-0.026)$ negatively correlated (Table 2$)$. The local cultivars "landraces" are most preferred by coffee growers for their quality and relatively high yield as believed and witnessed by most of the interviewed farmers. But most of the farmers' cultivars were susceptible to CBD. Despite the preference of landrace coffee types by the growers for typical liquor or cup quality, berries with big green bean size, and bean weight, have been observed to be susceptible to CBD.

Berhanu (2014) demonstrated that in some Hararghe coffee-growing areas, high CBD intensity was recorded on local landrace coffee types. Abdi and Abu (2015) also reported similar observations in Borena and Guji Zones. In many parts of Ethiopia assessed for coffee berry disease, most interviewed coffee growers indicated their preference for the local cultivars for their cup quality and yield potential (Kumlachew et al., 2016). 
Table 2. Correlation of important promoting factors and CBD intensities

\begin{tabular}{|c|c|c|c|c|c|c|c|c|}
\hline & Alt & FS & CL & Shst & Mgtop & Sev & Inc & Prev \\
\hline Alt & 1 & $.241^{*}$ & 0.027 & -0.097 & $0.275^{* *}$ & 0.012 & 0.013 & 0.015 \\
\hline FS & & 1 & 0.044 & -0.134 & 0.055 & 0.051 & 0.146 & 0.186 \\
\hline Vocg & & & 1 & 0.048 & -0.052 & -0.026 & 0.012 & 0.175 \\
\hline Shst & & & & 1 & 0.043 & -0.091 & -0.003 & -0.206 \\
\hline Mgtop & & & & & 1 & -0.2 & $-0.234 *$ & -0.111 \\
\hline Sev & & & & & & 1 & & \\
\hline Inc & & & & & & & 1 & \\
\hline Prev & & & & & & & & 1 \\
\hline
\end{tabular}

Note: Alt- altitude, FS-farm slope, CL- Coffee landrace grown, Shst- shade status, Mgtop- management option, SevSeverity, Inc- incidence, and Prev- prevalence

* and** Correlation is significant at the 0.05 and 0.01 probability levels, respectively.

\section{Conclusion}

To our Knowledge, this is the first paper related to assessment of CBD in Arsi coffee growing areas. Accordingly, CBD was prevalent in most surveyed areas, particularly at mid to high lands ( $\geq 1500$ m.a.s.l.). The overall average CBD severity and incidence in the surveyed areas were significant $(\mathrm{p}<0.05)$ among and within districts. The disease affected production and productivity of Arabica coffee in all assessed areas particularly the local cultivars which are more preferred by the growers for their bean weight and typical quality.

Therefore, stakeholders should take the following measure(s) in order to improve Arabica coffee production and productivity in coffee growing districts of Arsi. The former one is that high yielder and disease resistant coffee variety (ies) should be generated by testing coffee landraces with virulent pathogens using artificial inoculation. Cultural practices like pruning, shade regulation, fertilizer application and wider spacing should be utilized by growers in order to reduce CBD intensity throughout their coffee ecosystem.

\section{Acknowledge}

The authors would like to thank Mr. Mahammed Jundi and Mr.Girma Alemayo. And also Mechara Agricultural Research Centre and AGP- II for materials and financial supports, respectively.

\section{Reference}

[1] Abdi Mohammed and Abu Jambo. 2015. Importance and characterization of coffee berry disease (Colletotrichum kahawae) in Borena and Guji Zones, Southern Ethiopia. Journal of Plant Pathology and Microbiology, 6(9): 1-6 . doi:10.4172/2157-7471.1000302.

[2] Arega Zeru. 2006. Diversity of Arabica coffee populations in afromontane rainforests of Ethiopia in relation to Colletotrichum kahawae and Gibberella xylarioides. MSc Thesis, Addis Ababa Uni versity, Addis Ababa, Ethiopia, 99Pp.

[3] Bayetta Balachew. 2001. Arabica coffee breeding for yield and resistance to coffee berry disease (Colletotrichum Kahawae). Doctoral Dissertation. University of London, London, England.

[4] Bedimo, J., Bieysse, D., Njiayouom, I., Deumeni, J., Cilas, C. and Notteghem, J. 2007. Effect of cultural practices on the development of Arabica coffee berry disease caused by Colletotrichum kahawae. European Journal of Plant Pathology, 119(4): 391-400.

[5] Berhanu Tamiru. 2014. Coffee berry disease (Colletotrichum kahawae): status, pathogenic variability and reactions of coffee landraces in Hararghe, Eastern Ethiopia. International Journal of Plant Breeding and Crop Science, 2(1): 038-042. 
[6] Eshetu Derso. 1997. Coffee disease and their significance in Ethiopia (pp.723-26). In: Asic17th Kenya, Nairobi.

[7] Fekadu Alemu. 2013. Assessment of the current status of coffee diseases at Gedeo and Sidama zone, Ethiopia. International Journal of Advanced Research, 1(8): 192-202.

[8] IAR (Institute of Agricultural Research). 1997. Jimma national coffee research center progress report for the period 1994 (Part 1 Coffee). Melko.

[9] ICO. 2016. World coffee consumption. http://www.ico.org/prices/new-consumption-table.pdf.

[10] Kebati, R., Nyangeri, J., Omondi, O. and Kubochi, J. 2016. Effect of artificial shading on se verity of coffee berry disease in Kiambu County, Kenya. Annual Research and Review in Biology. 9(2): 1-11.

[11] Kimani, M., Little, T. and Vos, J. 2002. Introduction to coffee management through discovery learning. CABI, Nairobi, Kenya.

[12] Kumlachew Alemu, Girma Adugna, Fikre Lemessa and Diriba Muleta. 2016. Current status of coffee berry disease (Colletotrichum kahawae, Waller \& Bridge) in Ethiopia. Archives of Phytopathology and Plant Protection, 49: 421-433.

[13] Melaku Werede. 1984. Coffee genetic resources in Ethiopia conservation and utilization particular reference to CBD resistance (pp 203-211). In: Proceedings of the first regional workshop on coffee berry disease. 19-23 July 1982, Addis Ababa, Ethiopia.

[14] Mouen, B., Njiayouom, I., Bieysse, D., Ndoumbe, N., Cilas, C. and Notteghem, J. 2008. Effect of shade on Arabica coffee berry disease development. Journal of Phytopathology, 98: 1320 - 1325.

[15] Ntahimpera, N., Ellis, M., Wilson, L. and Madden, L. 1998. Effects of a cover crop on splash dispersal of Colletotrichum acutatum conidia. Phytopathology, 88: 536-543.

[16] Ntahimpera, N., Ellis, M., Wilson, L. and Madden, L. 1999. Comparison of rain effects on splash dispersal of three Colletotrichumspecies infecting strawberry. Journal of Phytopathology, 89: 555-563.

[17] Zeru, A, Assefa, F, Adugna, G. and Hindorf, H. 2009. Occurrence of fungal diseases of Coffea arabica L. in montane rainforests of Ethiopia. Journal of Applied Botany and Food Quality, 82: 148 - 151. 